\title{
Analysis of the Construction between Table Tennis Movement and College Campus Sports Culture
}

\author{
Qian Yang ${ }^{1}$ \\ ${ }^{1}$ Hubei University Of Automotive Technology, Shiyan City, Hubei Province, China
}

Keywords: Higher school, Campus culture, Table tennis, Culture construction

\begin{abstract}
College table tennis culture has its own unique structure and function of culture system, it is not only the important part of school culture, but it also has a rich campus subculture. On school culture, which is based on table tennis activities, multilateral coordination, full participation, can create a healthy, positive, upward table tennis campus cultural atmosphere, which also leads to the formation of students' sports consciousness and promote the construction of the campus sports culture play an important role.
\end{abstract}

\section{Introduction}

The development of the society, the first is the premise of the development of the people. Human potency and creativity are the most important resource of social development process, the ultimate goal of social development is to make people get all-round development itself [1]. Man's all-round development is "a process of improving survival, overall, the health, longevity, received a good education and a happy life is the basic symbol of human development"

As one of the modern athletic sports project, table tennis table tennis movement after more than a century of development, formed its own unique culture system, and become more influential in the world sports culture movement. The "people-oriented" cultural tradition main show is a kind of the humanism of the Olympic movement. The Olympic movement after the Renaissance movement, the liberation of people, a humanistic pursuit of all-round development of people, greatly promoted the society to human and the human body in the research, development, and finally gave birth to the modern sports humanistic spirit. To develop the modern sports of person and human is its own duty, the formation and development in the end [1]. Table tennis as a classic of the Olympic movement, it is fully embodies the humanistic spirit. And the humanities spirit also is people's mental and physical development as the core, think sports promote people's health, shape the perfect and harmonious development of personality and performance in the sense of humanistic care for human's own development.

\section{To promote the harmonious development of college table tennis culture idea}

Visionary people in the Chinese table tennis have been calling for the idea of globalization. It cannot deny the fact that the Chinese in the table tennis made great contribution in the development of globalization, China's table tennis poverty alleviation is already have a system to scale, but for table tennis to the less developed countries and regions, China can do is not only the hardware and software to help, more needs to be open from the attitude in the first place. And competitive table tennis only as part of the table tennis culture but not all, but during the development process of table tennis in the western countries the cultural essence of settle also needs us to draw lessons from. Outshine others not spring, flowers of spring [1]. As the NBA is in the United States, and from the perspective of the height of the international basketball sports culture, the NBA is the world, China must look around the world, to be actively involved in the international table tennis sports culture, on the one hand to Chong quintessence, east to learn feedback, contribute to the development of the world table tennis; On the other hand will continue to melt, travel, and to promote the continuous development of the Chinese table tennis culture localization.

For a long time, people have won all the gold medal of table tennis as a must to complete the task, while emphasizing won against the development of the project, without a doubt, there is no point; 
While emphasizes sport can't lose, too much emphasis on gold MEDALS. Gold medal is the highest point of view to make coaches and athletes in the usual training and competition of bearing heavy psychological burden, keeping competitive table tennis has become the first priority, and for the popularization of table tennis, table tennis market development [2]. Strong talent strength of China and the special training system, make originally in not good state more can't see the hope, they are not from get training the reserve talented person the idea of their own, but are used directly to introduce Chinese players instead of this crash the game strategy. So often seen in numerous international competitions represents a dialogue between Chinese athletes of different nationalities, and the country's table tennis still didn't get substantial development. If table tennis was win honor for our country, rouse national spirit, and played an important role in the political diplomacy, has an irreplaceable role in a certain period, then with the reform and opening, the economic boom, China's international status, the successfully held the 2008 Olympic Games in Beijing, the rapid development of the manned space program, in the face of the world financial crisis's strength, which is to win honor for our country, encouraging the manifestation of the national spirit, we have been able to just can experience strong sense of national pride in many ways, so should be gradually also table tennis in its true colors.

To further improve the existing system of talents cultivation. To explore the harmonious development of table tennis culture, you first need to consider the human factor. Because people are the creator of culture and tradition, different periods of the understanding of the value orientation of table tennis culture directly determines the training specifications of different athletes. China's current sports system is still the era of planned economy mode: professional sports teams belong to the local sports bureau director, mainly from the youth sports school athletes, in preparation to obtain corresponding treatment, namely after receiving salary, calculate length of service, and concentrate on training and competition from now on. For a fairly long period of time, such an arrangement makes less interference; the athletes in a relatively pure environment focus on the labor, can yet be regarded as human system [2]. But with the dramatic change of social environment, under the existing system, talent cultivation model clearly exposed the disadvantages: high selective cause waste of resources; Gold medalist center of ability training and value identity problem; Half militarization management caused by personal problems; One-sided development caused by the low quality of the athletes. And the core of the scientific concept of development is people-oriented, adheres to the people-oriented, is to in order to realize man's all-round development as the goal. Reflect on the mode of the cultivation of the athlete, is to set out to change the current training mode of professional sports old, change the athletes training one-sided, absolute value identity of athletes, tools, ignore the athlete's comprehensive development and the value of the phenomenon, truly people-oriented.

Outstanding table tennis culture industry attributes, go the way of harmonious development of table tennis culture. The formation of the Chinese table tennis culture localization features more depend on the sports system strong support, table tennis movement itself is lack of the ability of self development and self existence. With the establishment of the socialist market economic system, table tennis movement on the development road of mercerization, industrialization become a trend, sport industry attributes also should be a table tennis culture connotation [3]. And in this respect, as a model of sports globalization development, the development of the NBA's mercerization, industrialization provides valuable experience for China. Chinese table tennis also should bind to the market and use of national table tennis talent advantage, concentrated efforts to create the worlds largest, the highest level table tennis professional league, good exercise for the world to provide a platform to show skills. At the same time, should be the competition of competitive sport itself through propaganda products to attract more fans to watch the game. A large number of viewers competition will attract the attention of sponsors, the club will also result in the further development of the capital, which will continue efforts to improve the quality of the game. High levels of the game at the same time, it will attract the attention of the media, thus forming fans and the media, sponsors, sports, four aspects circulation chain, through the development of table tennis culture industry attributes, improve the survival and development of their own table tennis hematopoietic function. 


\section{Table tennis for the construction of campus sports culture}

Promote the popularization and development of table tennis. Table tennis culture and the relationship between action and reaction is table tennis. School table tennis movement can form has its own characteristics of table tennis culture, under certain conditions, school, and even the entire national table tennis table tennis culture will become the school sports popularization and to carry out the pilot, and this is need a process of accumulation in time.

School table tennis culture has guidance, the fusion effect. Every culture has its own value orientation, provisions of the people's pursuit of goals, has the function of guidance. Schools through table tennis culture has instilled students values, once grow to custom, the popular degree, will like other cultural forms to produce a mandatory norms, make the students very naturally and table tennis culture thought patterns, required by the code of ethics and code of conduct is consistent. It is also a table tennis culture fusion effect; it is a force for the invisible strong osmosis, affecting people's thought and behavior.

Western good state on the development of competitive sports in adolescent athletes training system is different from China. In America, for example, first of all, in terms of training system, has been combined with social road, the community and school played an important role in the process of cultivating juvenile athletes. Second, in the aspect of training of adolescent athlete's quality education attaches are great importance to the cultural education of adolescent athletes [3]. These teenagers' athletes no difference with the ordinary students, namely the basic attributes are students, and non-professional athletes. Even with excellent athletic ability to enter the university, must through the basic academic requirements prescribed by the school. Third, in terms of talent cultivation path, walk the path of combining teaching. If these players did well in the university sports teams, usually after graduation into the professional team. The model can effectively prevent the phenomenon of early professional athletes, not only can improve the comprehensive quality of athletes, the right of respect for athletes to receive education, and broaden the scope athlete employment choice.

Improve the students' own culture. Modern table tennis for a long time keeps a kind of civilization, polite, elegant cultural atmosphere. This atmosphere is derived from the years of traditional custom, the management of managers, and table tennis the willingness of the crowd. Modern table tennis culture not only retained the ancient civilization, polite and high table tennis, and enhances the modern sport mass, openness and service [4]. Table tennis not only can make the students take part in table tennis sports exercise, more can feel unique table tennis culture, learn to pay attention to your proper instrumentation, generous demeanor, treat people polite attitude, take good care of public property, have a sense of justice, the sense of responsibility, public spirit, etc. , really become the socialist modernization construction of useful talents, intellectual, physical all-round development.

\section{Higher school campus culture construction of table tennis}

Strengthen the construction of the table tennis club. Schools to establish table tennis club is a kind of mass sports organization, in the school sports commission, trade unions and school youth corps committee's leadership, organization hobby table tennis, staff and students to exercise and competition. School table tennis club operation without the economic base, to make the school table tennis club, will fluctuate in funds raised. First to club members thought idea, the cultivation of sports market awareness of members, charge a membership fee. Take is to the members, is to the members. Second to have the support of the school, through the improvement of the results of the competition, get the affirmation of the school leaders, staff and students, for part of base money [4]. Third should actively promote table tennis culture, the use of table tennis severity, interesting, can watch, strive for the support of the enterprise, the company, with its name or brand, as the name of the table tennis club or team, can obtain sufficient funds, and promote the enterprise, the company's image, to achieve mutual benefit.

College table tennis association and amateur club convergence. School table tennis extracurricular activities in the form of table tennis association, schools can provide venues, and large 
investment in amateur club because, at the same time, has the relative professional coach, just make up for the students in class only can learn knowledge of table tennis, both can foster strengths and circumvent weaknesses, make up for each other, so as to achieve a win-win situation [5].

Promote the university students' fitness function. Campus sports culture as a unique cultural phenomenon in the schools, in colleges and universities has been booming, body movement can not only improve and improve the working ability of the central nervous system, and to keep clear thinking, good memory ability [5]. People in the process of physical exercise, can quicken the circulation of the blood, and improve cardiac function, the function of the respiratory system. College students are in growth stage, to participate in the suitable sports, to lay a solid foundation for future health, make its normal growth and development, disease prevention cure, delayed healing, delay aging, prolong life.

To promote college students' entertainment. For members of the school life and spirit, the campus sports culture is a kind of good regulator, everywhere is sports school campus. This is sport special features. It is a part of the campus culture sports cultural life. It not only can work as a nervous learning the aftertaste of physical and mental recovery of the regulator, and can be further used as an entertainment, to enjoy the regulator, cheerful body and mind. Such as sports dance, ping pong balls, old disco, tai chi, all kinds of sports competition, etc. , in the campus life is always people form the specific regulation, the approximate form a pastime, but from the perspective of a physiological and psychological needs [5]. Through the body relax, athletic, enjoy science and nature, for spiritual and cultural life of the rich school members, provides the possibility. For recreation for the people provides the basic can inspire change conditions.

To promote the mental health of college students. With the development of The Times and social progress, people enjoy comfortable life brought about by science and technology and a variety of convenient at the same time, also suffered from mental stress in all its aspects. Studies have shown. Long-term stress not only can cause a variety of mental disorders, and many body diseases are also associated with mental stress, such as high blood pressure, heart disease, cancer, etc [6]. Sports can ease the mental stress, prevent all kinds of disease is the fact that scientific research has confirmed. And table tennis as a sport, with its graceful, harmonious and comprehensive physical exercise, which also has a strong beat is famous for its music accompaniment, is a welcome antidote ease the mental stress. With the rhythm of the cheerful music do ping pong balls, produce a kind of dance, psychological trend of yearning and pursuit of beauty, feel the flavor of the happy, cultivate and help practitioners in a best state of mind, so as to ease the mental stress, make the person has a stronger vitality. Exercise muscle often have to work to the limit, soreness and fatigue, and table tennis is in a strong music accompaniment, can make the person of ecstasy, in imperceptible in developing the practitioner determination of quality. In addition, the people who take part in the table tennis exercise from the social from all walks of life [6]. Thus expand the people's society, the people from a single work and home environment, can contact and know more people. Joy together and encourage each other, some people became lifelong friends. Therefore, ping-pong exercise not only can strengthen physical health, but also has the entertainment function, can make the person a kind of spiritual enjoyment in the exercise, to meet people's psychological needs.

College students' intelligence improvement. Table tennis is at the mercy of the adjustment in the central nervous system. In turn, by ping-pong exercise can enhance the function of the central nervous system [6]. Ping-pong movement routes, direction, speed, type, strength, such as changing, can make the practitioners observation and imitation, action and reproduce the force to strengthen memory, improve the flexibility of nerve system and proportionality, all-round development of man's coordination, improve their diathesis and temperament, the further development of creative thinking, to make me wild wide, keen perception and analysis of comprehensive ability enhancement, exuberant vitality.

\section{Summary}

Table tennis culture is a subculture of social culture, campus to spread an important function of social culture. Table tennis culture, therefore, should keep close contact with society, take the 
initiative to go out and bold, please come in. On the basis of pay special will be attention to the group activities, to strengthen the construction of sports culture. Table tennis culture spreads in school, not only make the students master and improve the table tennis technique, obtained the exercise of body and mind, and through the table tennis culture causes the student to set up the correct outlook on life, values, no matter what kind of future work will be affected by the table tennis culture, so as to realize and achieve the goal and the pursuit of life. Table tennis culture has good development prospects for table tennis and Chinese table tennis level enhancement, is of great significance.

\section{References}

[1] J. X. Song, Athletics education, Beijing: people's sport publishing house, 1999, pp. 22-26.

[2] H. Y. Wang, School table tennis hot forecast for the 21st century China, Sichuan sports science, 2007, vol. 1, pp. 42-46.

[3] Li Xilai, theory of the campus sports culture construction and development, xi 'an sports college journal, 2013, vol. 5, pp. 32-36.

[4] Zh. X. Tao, China's present situation and development countermeasure research, table tennis athletics sports journal of Peking University, 2005, vol. 5, pp. 70-75.

[5] X. L. Li, Ping-pang sports culture construction and development, Xi'an sports college journal, 2014, vol. 5, pp. 51-56.

[6] W. R. Li, Table tennis culture is analyzed for school students, the influence of sports academic world, 2006, vol. 3, pp. 15-19. 